\author{
Ю.В. Верба
}

\title{
СМЫСЛОВЫЕ КОНФИГУРАЦИИ ФИЛОСОФИИ ВИКТОРА ФРАНКЛА
}

\begin{abstract}
Аннотация. Предметом исследования является ряд смысловых конфигураций философии В. Франкла. Уделяется внимание духовному бессознательному, глубинной части человеческой психики с его сущностными желаниями: любовь, свобода и ответственность, а также тому, что отчуждение от него приводит к утрате смысла и экзистенциальному вакууму. Понятие "смысл» рассматривается как центр, вокруг которого можно собрать расколотое человеческое существо в телесно-душевно-духовное челое. Рассматриваются также понятия "Бог» и "вера», которые имеют у Франкла особое значение.

В своей работе автор использует принцип историзма, а также методы и подходы философско-антропологического исследования.

В процессе исследования раскрыты новые грани проблемы экзистенциального вакуума и обозначены позитивные пути для его преодоления. Были выявлены смысловые конфигурации, имеющие большое значение для более глубокого понимания природы человека, а также противоположные смыслу "антисмыслы», отражающиеся в тенденциях «гипер» и "псевдо».

Ключевые слова: смысл, духовное бессознательное, экзистенциальный вакуум, логотерапия, вера, Бог, дух, антисмысл, гуманизм, любовь.

Abstract. The subject of the research is a number of conceptual configurations in Viktor Frankl's philosophy. The author of the article pays attention to the spiritial unconcious as an in-depth part of the human psyche with all the essential desires such as love, freedom and responsibility. The author also focuses on the fact that alienation from one's spiritual unconcious leads to the loss of the meaning of life and existential vacuum. The term 'meaning' is viewed as the core that brings together a broken human being and unites body, spirit and soul. The author also touches upon such issues as 'God' and 'faith' that have a special meaning in Viktor Frankl's philosophy. In this research the author has used the principle of historicism as well as methods and approaches of philosophical anthropology. In the course of the research the author reveals new sides of the problem of existential vacuum and outlines positive ways for overcoming existential vacuum. The author also defines conceptual configurations that play an important role for a better understanding of human nature as well as describes so-called 'anti-meanings' that are usually reflected in 'hyper' and 'pseudo' tendencies.
\end{abstract}

Key words: love, humanism, anti-meaning, spirit, God, faith, logotherapy, existential vacuum, spiritual unconscious, meaning.

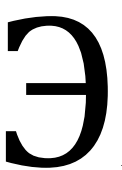
кзистенциальный вакуум... Данный термин, ставший в каком-то смысле символом целого феноменального комплекса состояний современного человека, связанного с «ноогенным неврозом», или потерей смысла жизни, - ввёл Виктор Франкл. Если экзистенция - это живое человеческое существование, постоянный выбор возможностей, творческое формирование человеком самого себя, беспрестанное движение, не прекращающееся до самой смерти, трансцендирование. То вакуум - это ничто, полная пустота лишённая каких-либо объектов, где нет никакого движения и развития, нечто мёртвое, безжизненное... Вспоминаются слова известного современного поэта, который говорил об «умирании мучи- тельной жизнью». Не о таком же феномене он вёл речь?.. Иногда Франкл называл это «переживанием бездны» - отчаяние от падения в никуда, когда не за что зацепиться в этом падении, и впереди - тоже ничего.

За этим образным, красиво-благозвучным выражением скрывается вполне узнаваемое современным человеком состояние. Вряд ли найдётся тот, кому оно совершенно незнакомо. Вопрос лишь в интенсивности и продолжительности. И до тех пор, пока это ощущение возникает в душах людей, пока у человека есть стремление освободиться от жизненной пустоты, ощутить наполненность и смысл жизни - философия Франкла с её центральным ядром - смыслонахождением - будет 


\section{Психология и психотехника 9(96) • 2016}

оставаться актуальной. И что ещё очень важно автор обладает неиссякаемой верой в человека и человечность, в его произведениях отсутствуют осуждения и критика человека как некоего изначально порочного, недостойного существа. Напротив, он исследует те глубинные качества природы человека, находящиеся в его духовном бессознательном (термин Франкла), которые дают небезосновательную надежду на светлое будущее человечества. В этом смысле произведения Франкла подобны глотку свежего воздуха в удушающей атмосфере множества более мрачных прогнозов.

Рассуждения Франкла о смысле, его философия смысла в достаточной степени исследована российскими и зарубежными специалистами философами, психологами, социологами, педагогами и др. Кажется, что на огромном «материке» творчества Франкла практически не осталось белых пятен. При этом в его работах встречается ряд смысловых конфигураций, которые требуют более тщательного анализа, обнаружения новых аспектов и более вдумчивой трактовки. Обозначить их, акцентировать внимание на их важности для более полного выявления указанных Франклом новых, нетривиальных путей освобождения человека от экзистенциального вакуума - и есть цель написания данной статьи.

Сначала хотелось бы обозначить те смысловые конфигурации философии Франкла, которые, на мой взгляд, являются принципиально важными, но не вполне исследованными, а затем рассмотреть каждую из них более внимательно:

- смысл как ядро, центр, вокруг которого можно собрать «расколотое» человеческое существо в телесно-душевно-духовное целое;

- духовное бессознательное - глубинная часть психики;

- антисмыслы «псевдо» и «гипер».

Вопрос смысла всего сущего - один из самых актуальных для человечества. Люди испокон веков его искали и выражали с помощью религии, искусства, философии, а позднее - и науки.

Религиозные люди ищут и реализуют смысл с помощью веры, считая, например, земную жизнь человека некоей подготовкой его души к вечной жизни после смерти. Правильно прожив жизнь, реализовав в ней высший (Божий) замысел, возможно в будущем обрести вечную жизнь с Богом (христианство, ислам). Другие считают, что смысл человеческого бытия - в познании Брахмана (веданта), достижении Кайвальи, совершенного духовного освобождения (йога), в избавлении от всех страданий и достижении Нирваны (буддизм), в слиянии с Дао (даосизм) и т.п.
Творцы пера, кисти, нот - субъективно, интуитивно, во многом иррационально раскрывают озарения смысла бытия в своих произведениях.

Учёные в своих гуманитарных и естественных исследованиях стараются получить некие объективные знания. Хотя, как отмечает Франкл, в современных науках, описывающих мир, есть «отсутствующее звено», они «слепы к нему», и это как раз вопрос о смысле: «Зачем?».

Постижением глубинной сути смысла занимаются философы, идя дальше религии, задавая направление наукам, предлагая свои ответы на вопросы «Зачем?», «Почему?», «С какой целью?».

Философия Франкла более всего близка к идеям экзистенциалистов, которые считали, что смысл жизни индивидуален, что человек сам находит его, сам творит свою жизнь и сам несёт за это ответственность. Также можно сказать, что смысл у Франкла является неким ядром, центром, вокруг которого возможно «собрать расколотое» [1], многомерное существо - человека, чтобы он ощутил свою целостность, освободился от мучительных противоречий и конфликтов, проистекающих из самой его природы, его разделённости на тело и дух, сознание и бессознательное, разум и чувства и т.д., чтобы жизнь его стала по-настоящему человеческой, экзистенциальной.

Если многим философам проблема одновременной взаимосвязи и противостояния столь различных сфер человеческого существа казалась неразрешимой, то Франкл решает эту проблему, рассматривая человека как «телесно-душевно-духовное целое». И именно понятие «смысл» является объединяющим центром, способствующим установлению «гармонии между составляющими человеческого естества» [2]. Отсутствие смысла в жизни человека равнозначно отсутствию центрального ядра, скрепляющего центра, который как магнит может притянуть к себе, объединить и заставить «вращаться» вокруг себя все составные части человека. Образовавшись посреди экзистенциального вакуума, это смысловое ядро способно стать центром телесно-душевно-духовного целого. И практика логотерапии Франкла, базируясь на его философии, является уникальной программой такого «собирания» человека на индивидуальном уровне.

Самой глубокой частью психики человека Франкл считает духовное бессознательное. Что это за феномен? Духовное бессознательное находится над биологической и инстинктивной сферами человека, это также значительно более глубинная часть психики, чем индивидуальное, семейное, расовое и даже коллективное бессознательное, 
исследованные 3. Фрейдом и К. Юнгом. Оно шире любых универсальных архетипов. Это источник подлинных желаний человека, которые делают его именно человеком: стремление к любви, свободе, познанию, индивидуальному, социальному и трансцендентному смыслу жизни, вера. В современной философской и научной литературе понятие «дух», к сожалению, отсутствует. Однако без него многие человеческие проявления невозможно объяснить лишь на телесном и психическом уровнях, например, стремление человека постичь смысл жизни и смерти, Бога, а также само по себе самосознание человека, его свобода и ответственность. Исследование духовной природы человека роднит Франкла с такими русскими философами, как В. Соловьёв и Н. Бердяев. Франкл подчёркивает, что «логос» на греческом языке означает не только «смысл», но также «дух», и логотерапия затрагивает именно духовное измерение человека.

В духовном бессознательном отсутствует какое бы то ни было зло. Оно способно одухотворять любые более низкие проявления человека, если конечно он не теряет с ним связь. Связь теряется из-за «забаррикадированности» духовного бессознательного, которое начинается с подавления человеком «голоса совести», ведь именно на «языке совести» происходит общение между духовным бессознательным и человеком. И тогда стремление к смерти и разрушению берёт вверх над стремлением к жизни и созиданию, человек отчуждается от других людей и живых существ, утрачивает чувство со-причастности, со-бытия, утрачивает смысл. В худшем случае это приводит к саморазрушению, внутренним и внешним конфликтам, патологической жажде власти, войнам, эксплуатации, и т.п.

С другой стороны, наиболее явственно духовное бессознательное проявляется, когда человек забывает о себе, отдаётся сполна какому-то делу или своему партнёру через служение, и особенно через любовь. В любви он раскрывает сполна свои лучшие потенциалы, а также способен пережить опыт подлинного познания и ощущение реальности, единение субъекта и объекта. В восточных йогических школах такое единение называется медитацией, и говорится, что с её помощью можно достичь просветления, т.е. обрести подлинные знания о реальности и всегда пребывать «в духе». Благодаря любви-единению осуществляется постижение сущности другого человека во всей глубине. Благодаря любви как духовному акту человек помогает раскрыть в любимом все его наилучшие черты и свойства, даже те, которые находятся в потенциале, и воплотить их в жизнь. Т.е. любовь помогает другому человеку понять, кем он должен быть, иначе говоря, реализовать свой смысл. Так что любовь наполняет смыслом и жизнь того, кто любит, и жизнь того, кто любим.

Свобода - тоже одно из сущностных желаний духовного бессознательного. У человека есть инстинктивные влечения, но они не исчерпывают его, он может их и признавать, и отрицать. Наследственность и среда тоже не могут сполна повлиять на человека. Ибо духовное бессознательное сильнее инстинктов, наследственности и среды. Поэтому, в конечном счёте, человек решает за себя сам. Эта подлинная свобода, проистекающая из духовного бессознательного, неразделима с ответственностью. И ответственность человека заключается в реализации ценностей (созидательных и ценностей переживания). По сути, это связано с вопросом правильного выбора ценностей. И ещё понимания, за что, перед чем и перед кем человек несёт эту ответственность. «За что» - имеются в виду выбор ценностей и смысла. «Перед чем» - перед своей совестью, которая является «органом смысла». Но при этом есть ещё «некто», с кем человек ведёт диалог, и «мы должны стать последними, кто не решался назвать эту... сверхличность тем именем, которое ей дало человечество: Бог» [3, с. 126].

Слово «Бог» у Франкла имеет особое значение. Как минимум, его философия, с верой в существование некоего разумного высшего начала и целесообразность бытия, телеологична. Но также нередко он прямо говорит и о Боге как о некоем незримом наблюдателе, «Великом Зрителе», и, в то же время, режиссёре спектаклей человеческих жизней. Личная вера Франкла, его собственное мировоззрение, безусловно, оказали влияние и на его философию и теорию логотерапии. «Логотерапия не выходит за границы научного знания в область теологии, но, в отличие от других психотерапевтических систем, она оставляет открытым путь от человека к сверхчеловеческому высшему существу, она эту связь однозначно не закрывает» [4, с. 268].

По мнению Франкла, высший, трансцендентный, предельный, абсолютный смысл, или «сверхсмысл» (термин Франкла) сполна непостижим человеком. Точно так же, как человеческая свобода - это не вседозволенность и не всемогущество, так же и человеческая мудрость - это не всезнание. Окончательное, полное понимание «сверхсмысла» бытия - откуда мы пришли и куда идём, есть ли Бог и какова цель Его Творения - кажется находится за пределами возможностей человеческого разума, но поскольку наша реальность такова, что мы, человеческие существа, уже есть, существуем, то для нас всегда актуальными будут вопросы: «Для чего всё это?», «Какой в этом смысл?». И вера в этот 


\section{Психология и психотехника 9(96) • 2016}

сверхсмысл играет большое философское и психотерапевтическое значение. Эта вера - одно из действенных средств, применимых в любых ситуациях человеческой жизни, особенно в тяжёлых. Когда все другие средства исчерпаны, когда человек сделал всё возможное, когда уже никто и ничто не может помочь - вера может сотворить чудо. Именно она отчаянный возглас: «За что?!» может превратить в глубинное осмысление «Во имя чего?». «Жизнь обладает безусловным смыслом, и нам нужна безусловная вера в это», - утверждал Франкл.

С другой стороны, в жизнь современного человека всё более проникают две противоположные тенденции, «псевдо» и «гипер», которые можно назвать «антисмыслами».

Эта тема появляется в рассуждениях Франкла о языке нашего общения, о том, как и для чего мы им пользуемся. Изначально язык - это средство донесения смысла. Но бывает, что сказанное нами не передаёт реальности, лишено смысла. И тогда язык становится «псевдоязыком», языком без сути, без логоса. И действительно, тут впору задуматься. Как и о чём мы общаемся? Сполна ли мы используем этот инструмент - язык - для подлинного понимания друг друга? Всегда ли наши слова наполнены смыслом, не являются ли они простыми шаблонами, стереотипными перебрасываниями звуковых вибраций, от которых ни тепло и ни холодно ни уму, ни сердцу, лишь тратятся драгоценные минуты жизни, которые можно было бы посвятить подлинному, субстанциальному ее проживанию? Особенно это касается наших ежедневных встреч с другими людьми, поверхностное общение с которыми стало некоей тяготящей «нормой». Подобное «общение» является не чем иным, как показателем социального и эмоционального отчуждения и того же экзистенциального вакуума. И оно же продолжает их усиливать. Франкл называет его «диалог без логоса». А также даёт ещё более жёсткие определения: «псевдообщение», «псевдовстреча».

С другой стороны, вроде бы желая научиться взаимодействию с другими, чтобы тем самым преодолеть отчуждение, люди встают перед проблемой неумения общаться искренне. Франкл приводит в пример встречи в группах гуманистической психологии. Люди встречаются и пытаются испытать другу к другу любовь при отсутствии реальных чувств, искусственно оказать друг другу какие-то знаки внимания. Но это происходит насильно, без понимания природы чувств, без понимания подлинного смысла общения и любви. Подобная «гиперинтенция» на корню рубит искомый результат. Например, когда человек излишне сконцентриро- ван на желании получить удовольствие от секса, он упускает из виду подлинное счастье, которое возможно испытать во взаимоотношениях, основанных на сердечной любви.

Что тут происходит? Человек концентрируется на своём желании испытать какие-то приятные эмоции, чувство любви и дружбы от общения или сексуальных отношений - и он начинает ради этой цели буквально эксплуатировать людей и отношения с ними. Экзистенция, живое чувство теряется, отношения и люди становятся простыми средствами для удовлетворения личного чувства удовольствия и счастья. От такого отношения к другим людям как к неживым предметам, вещам предостерегал ещё Э. Фромм [5]. При этом нет подлинной любви к человеку, нет погружения в его бытие, нет подлинного понимания другого, нет искреннего желания сделать его счастливым. А ведь именно такая интенция в итоге делает по-настоящему счастливым и приносит удовлетворение. Поэтому нет ничего удивительного в том, что нездоровая гиперинтенция, т.е. повышенное, безудержное, слепое стремление реализовать своё собственное желание удовольствия - оборачивается крахом. Она искусственна, нежизнеспособна, и искомая цель не достигается.

А ещё встречается «гиперрефлексия», что означает концентрацию сверх меры на самом себе и своих собственных внутренних переживаниях. Пытаясь понять себя, человек наоборот - теряет самого себя, ещё больше запутывается и опять погружается в экзистенциальный вакуум. Эти самокопания нередко подменяют человеку смысл жизни, отвлекают его от реального поиска, реальных открытий, реальных взаимоотношений с миром и грозят усугублением всевозможных неврозов.

Итак, тенденция «псевдо» - характеризует внутреннюю пустоту, отсутствие реального проживания, смысла в явлении, эссенции в экзистенции. Отсутствие глубины чувств приводит к «псевдо-чувствованию». Неумение, а точнее, нежелание глубоко думать, размышлять - порождает явление «псевдо-мыслие». Постоянное повторение маленьких псевдо-поступков приводит в конечном итоге к псевдо-жизни.

Тенденция «гипер» - показатель той же самой внутренней пустоты, для избавления от которой человек прикладывает упорные усилия без понимания, без чуткости, неестественно (искусственно). Эта тенденция тоже ведёт, в конечном итоге, к ещё большему опустошению, которое на этот раз возникает из-за пресыщения от всевозможных видов «центробежного досуга» (термин Франкла), профессиональной сверхактивности, повышенной 
интенции, направленной на получение удовольствия и т.п. Но реальный голод так и не утоляется... Это отчасти похоже на переедающего человека, располневшего и страдающего от своей полноты, но неспособного остановиться, ощущающего ещё больший голод и неудовлетворённость, чем перед началом переедания. Сюда же относится гиперинтенция в отношении денег и секса. Деньги и секс воспринимают как цель, хотя правильнее их было бы рассматривать как средства для реализации смысла.

Можно говорить о том, что эта проблема возникает из-за смещения фокуса внимания человека в сферу физическую, материальную, телесную, «вещную» при недостаточном внимании к двум другим сферам, психической и духовной. И особенно сильно отчуждение от духовного бессознательного. Баланс в телесно-душевно-духовном целом, к которому стремится человек, нарушен. Ощущение экзистенциального вакуума ещё больше усиливается.

Логотерапия даёт действенные методы восстановления этого баланса. И об этом - все книги Франкла. Я ещё раз коснусь лишь смысловой конфигурации «любовь» в аспекте восстановления данного баланса.

Поверхностный флирт, сексуальные связи без любви, проституция, отношение к партнёру как к вещи, ревность с одной стороны и измены с другой, всевозможные виды неестественных сексуальных связей - всё это издержки современного «эротического материализма» [3, с. 262], признаки утери смысла любви. Погружаясь в «эротический материализм», человек находит заменители любви, придумывает нечто, что заполняет его экзистенциальный вакуум. Воистину, если смысл любви потерян - мы начинаем его придумывать. Наша сущностная, сугубо человеческая «жажда интимности» замещается различными суррогатами, и встреча двух людей превращается в псевдовстречу. При подлинной же встрече и любящий, и любимый переживают «внутреннее обогащение», для них «вся вселенная расширяется и углубляется» [3, с. 245]. Соприкосновение с другим человеком происходит на трёх уровнях: физическом, психическом и духовном. Причём в настоящей любви тело является не первичным элементом, а всего лишь «средством самовыражения». В теле любимого отражается наполненность его внутреннего мира. Соприкосновение двух тел - это своего рода символ, смысл которого гораздо более глубок. Любовь «использует тело» для выражения «духовной связи, которой на самом деле является любовь» и «именно любовь, духовный акт, придаёт сексуальной связи человеческое достоинство» [3, с. 251]. Придание иного смысла физической любви обрекает человека на ощущение бессмысленности.

Очень показательной для понимания философии Франкла, в том числе его взгляда на духовное бессознательное, является пьеса «Синхронизация в Биркенвальде». В этой пьесе, всего лишь на нескольких страницах, в художественных образах Франкл выразил суть своей философии. И в заключении мне хотелось бы проиллюстрировать это.

Действие пьесы проходит в двух измерениях: земном и метафизическом. А также в ней есть ещё одно измерение - невидимого великого Зрителя спектаклей человеческих жизней. Именно Он даёт жизнь, и Он же её забирает. Его никто не видит, в Него можно только верить...

В метафизическом измерении проходит вневременная и внепространственная конференция философов из разных эпох: Сократа, Спинозы и Канта. Они, в основном едины в своих мнениях и даже являются верующими людьми. Так, Кант вслед за Спинозой однажды восклицает: «Слава Богу!» (при скептическом замечании Сократа: «И это называется - атеист»). В этом отражена франкловская идея о духовном бессознательном, которое есть в каждом человеке, независимо от его отношения к религии, и, конечно же, лучшие представители человечества очень близки к нему. Однако такое приближение непросто. Как говорит Сократ, их собственная глубинная мудрость была при жизни оплачена кровью, страданием, нуждой и, наконец, смертью.

С беспокойством философы наблюдают человеческий мир 1946 года, после двух мировых войн, видя разрушение морали, смерть людской веры и в Бога, и в любые идеологии, и в самих себя. Люди не верят мудрецам, не хотят объединяться и вместе стремиться к благу. Т.е. налицо сильное отчуждение людей от духовного бессознательного.

Тогда эти философы решают повлиять на людей с помощью искусства, игры, театра, отразив истину в символической форме, превратив в сцену саму жизнь. И сами они переносятся в земной мир, в концлагерь, становясь свидетелями высочайших проявлений стойкости духа посреди нечеловеческих, адских условий, которую демонстрируют братья Карл и Франц. В образе Франца угадывается сам Франкл. Именно в его уста он вкладывает свои собственные понимания смысла жизни, страданий, смерти, жертвы и т.п.

Чтобы испытать Карла, Великий Зритель посылает на землю ангела в виде эсесовца, который жестоко допрашивает его, пытает, и в ко- 


\section{Психология и психотехника 9(96) • 2016}

нечном итоге убивает. Карл достойно принимает смерть, не совершив предательства, поднявшись над слабой человеческой природой, доказав свой смысл. Ангел внутри эсесовца восхищён его мужеством. И после смерти Карл, попав на небеса, выражает благодарность этому ангелу, сыгравшему роль эсесовца, который его убил, «желая только добра».

И далее уже Франц говорит, что на самом деле никто не дьявол с рождения, даже эсэсовцы. И если ему удастся выжить, то после войны он хотел бы оправдать тех эсесовцев, которых в приступе мести захотят судить, несмотря на то, что на самом деле они не желали делать зла. Когда другие заключённые, услышав это, негодуют и называют Франца предателем, он отвечает, что не предал главное - человечность. И произносит пламенную речь о подлинной человечности, воссоединяясь со своим духовным бессознательным, что объединяет его образ с образом Христа, проповедовавшим новую мораль в Нагорной проповеди.

«ФРАНЦ: Ненавистью отвечать на ненависть? Несправедливостью на несправедливость? Чтобы мы делали то же, что они? Чтобы мы обращались с ними так же, как они с нами? Это - не справедливость. Это увековечит бесправие.

ПАУЛЬ: Око за око, зуб за зуб... Ты забываешь это.

ФРАНЦ: Только не ссылайся на Библию! Тебе очень легко понять её превратно. Да и знаешь ли ты её по-настоящему? Проверить тебя? Тогда скажи, зачем Господь наложил печать на Каина, убийцу Авеля?

ПАУЛЬ: Ясно, зачем. Чтобы его всюду узнавали, чтобы опасались его, вели себя с ним соответственно.

ФРАНЦ: Неверно! Этот знак, эта печать должна была как раз охранять Каина, чтобы с ним ничего не случилось, чтобы его не наказывали больше, потому что он уже наказан Господом. Понимаешь? Подумай, что бы случилось, если бы было иначе. Убийства бы просто не прекращались, потому что одно влекло бы за собой другое, одна несправедливость тянула бы за собой другую. Нет! В конце концов, цепь зла должна быть разорвана! Мы не хотим снова и снова платить за ненависть - ненавистью, за насилие - насилием! Это цепь, Пауль, пойми, цепь - вот что это! Её нужно наконец разорвать...».

А затем Франц совершает ещё один поступок. В концлагере он мечтал дописать свою пьесу, по поводу чего он испытывал сильные мучения. Но тут он принимает смелое внутреннее решение отказаться от этого желания. Т.е. он отбрасывает своё последнее личное желание: не умереть без- вестным, оставить о себе память. Этим отказом от антисмысла, пресечением гиперинтенции, Франц «обретает самого себя», теперь сама его жизнь живая пьеса, где он - свободный автор, способный сделать из своей пьесы-жизни настоящий шедевр. В этот момент Франц чувствует себя ближе всего к истине, к её сути, ощущает настоящий духовный экстаз. В момент, когда он готов пожертвовать своей жизнью ради других - на небесах его «приговаривают к жизни». И осознав, что ему ещё предстоит жить, выжить в жутких условиях, дописать пьесу своей жизни наилучшим образом - он обретает веру - веру в себя, веру в своих родных и близких веру в смысл жизни и смерти [6].

Итак, философия и логотерапия Франкла не теряют своей актуальности и сейчас, особенно в условиях современного экзистенциального вакуума. Его исследования духовного бессознательного очень важны для более глубокого понимания природы человеческого существа и нахождения новых позитивных путей развития человечества. Смысл - это ядро, центр, вокруг которого можно собрать «расколотое» человеческое существо в телесно-душевно-духовное целое. При этом также важно быть внимательным к подмене подлинных смыслов «антисмыслами».

Одна из самых сильных смысловых конфигураций не только философии, но и всей жизни Виктора Франкла - хотя он и не учит этому директивно, но выражает и в своей пьесе «Синхронизация в Биркенвальде», и всей своей жизнью - это «прерывание цепи». Речь идёт о цепи зла, несправедливости, темноты жизни. Франкл уверен, что её можно прервать только собственной жертвой. Но здесь стать жертвой - не обязательно означает принять смерть. Жить в полном соответствии с духовным бессознательным - вот что необходимо.

Д.А. Леонтьев писал о Франкле: «Мало кого можно вспомнить в истории человечества, кто заплатил столь высокую цену за свои убеждения и чьи воззрения подверглись такой жестокой проверке. Виктор Франкл стоит в одном ряду с Сократом и Джордано Бруно, принявшим смерть за истину» $[6$, с. 5]. Имея возможность уехать из страны и избежать концлагеря, Франкл сознательно не сделал этого, оставшись для поддержки престарелых родителей, не имевших шанса уехать с ним. И это было равнозначно готовности пойти на смерть. Думаю, человечеству ещё предстоит подняться на такой уровень гуманизма и осознания Смысла, примером которого является вся жизнь, деятельность и философия Виктора Франкла. 


\section{Список литературы:}

1. Гуревич П.С. Расколотость человеческого бытия. М.: ИФ РАН, 2009. 199 с.

2. Гуревич П.С. Философская антропология. М., 2010. 607 с.

3. Франкл В. Человек в поисках смысла. М.: Прогресс, 1990. 368 с.

4. Франкл В. Московские лекции 1986 года // Проблема смысла в науках о человеке (к 100-летию Виктора Франкла): Материалы международной конференции. М., 2005. С. 245-273.

5. Фромм Э. Иметь или быть? М.: АСТ, 2014. 320 с.

6. Франкл В. Сказать жизни “ДА!” Психолог в концлагере. М.: АНФ, 2015. 240 с.

7. Фрейд 3. Я и Оно. М.: Эксмо-Пресс, 2016. 864 с.

8. Юнг К.Г. Архетип и символ. М.: Ренессанс, 1991. 304 с.

9. Леонтьев Д.А. Психология смысла: природа, строение и динамика смысловой реальности. М.: Смысл, 2003.487 с.

\section{References (transliterated):}

1. Gurevich P.S. Raskolotost' chelovecheskogo bytiya. M.: IF RAN, 2009. 199 s.

2. Gurevich P.S. Filosofskaya antropologiya. M., 2010. 607 s.

3. Frankl V. Chelovek v poiskakh smysla. M.: Progress, 1990. $368 \mathrm{s.}$

4. Frankl V. Moskovskie lektsii 1986 goda // Problema smysla v naukakh o cheloveke (k 100-letiyu Viktora Frankla): Materialy mezhdunarodnoi konferentsii. M., 2005. S. 245-273.

5. Fromm E. Imet' ili byt'? M.: AST, 2014. $320 \mathrm{~s}$.

6. $\quad$ Frankl V. Skazat' zhizni “DA!” Psikholog v kontslagere. M.: ANF, 2015. 240 s.

7. Freid Z. Ya i Ono. M.: Eksmo-Press, 2016. 864 s.

8. $\quad$ Yung K.G. Arkhetip i simvol. M.: Renessans, 1991. 304 s.

9. Leont'ev D.A. Psikhologiya smysla: priroda, stroenie i dinamika smyslovoi real'nosti. M.: Smysl, 2003. 487 s. 